\title{
From Positivism to Realism: The Philosophy of Gustav Bergmann
}

WILLIAM HEALD

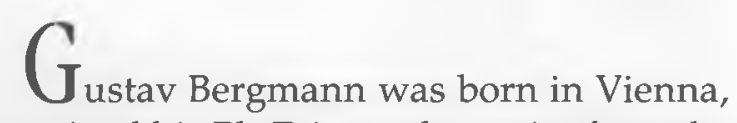
Austria, in 1906. He received his Ph.D in mathematics from the University of Vienna in 1928. Shortly before he received this degree he was invited by Friedrich Waismann to attend a weekly series of meetings of philosophers, scientists, mathematicians and other intellectuals under the guidance of Moritz Schlick, a group that has since become known as the "Vienna Circle" and is generally associated with the philosophical movement known as "logical positivism". In 1931 Bergmann accompanied Walter Mayer, his dissertation advisor, to Berlin, Germany, where they both worked with Mayer's friend Albert Einstein, assisting him with some of the more complex mathematical aspects of his work in physics.

At this time it was nearly impossible for someone who was Jewish (as Bergmann was) to teach at a university level in either Germany or Austria; ambitious Jewish intellectuals were more or less restricted to a career in medicine or law. For this reason Bergmann reentered the university, and finally received a law degree from the University of Vienna in 1935 . He worked as a corporate lawyer until 1938, at which time the level of Nazi domination of Austria had become so pervasive that Bergmann was forced to leave. His first stop was the Hague where Otto Neurath gave him enough money to enable emigration to the United States. Once in the U.S. Bergmann briefly worked for an insurance company in New York City, where he contemplated becoming an accountant. He was invited instead to Iowa 
City, Iowa, to work with the Gestalt psychologist Kurt Lewin, who was at that time working for the Iowa Child Welfare Research Station. Lewin was at the time attempting to apply mathematical topology to his work in psychology and Bergmann had a degree of expertise in this area, as well as a measure of familiarity with experimental psychology and psychoanalysis. Bergmann accepted a one-year position with Lewin as a research associate and travelled with him to Harvard and Berkeley. The association did not last long as Bergmann became convinced that Lewin's programmatic intentions were untenable, but through it Bergmann met many psychologists at The University of Iowa and elsewhere in the U.S. with whom he did subsequently enjoy intellectually fruitful relationships (Kenneth Spence of The University of Iowa, most notably).

Appointed as a temporary "lecturer" in philosophy in the early 1940s at The University of Iowa, Bergmann was soon made an assistant professor (1944) and by 1950 had become a full professor in both the Philosophy and Psychology departments. In 1967 Bergmann was elected president of the American Philosophical Association and in 1972 became a Carver Professor. Officially retired in 1974, he continued to teach in the Psychology department for two more years and continued to write and do research in philosophy until his death in 1987.

As soon as Bergmann had become attached to The University of Iowa he began writing and publishing articles about philosophy. At first, as might have been expected, many of his concerns were with the philosophy of science and scientific method, especially the methodology of psychology. Bergmann's thoroughgoing commitment to the empiricistic methods of the natural sciences coincided exactly with the outlook of the "working" psychologists at The University of Iowa, who believed that the proper method of psychology consisted of observation of behavior and explanation of behavior in terms of stimulus-response mechanisms. Nevertheless, as a philosopher (and not merely a philosopher of science), Bergmann was emphatically not a behaviorist. That is, while he did believe 


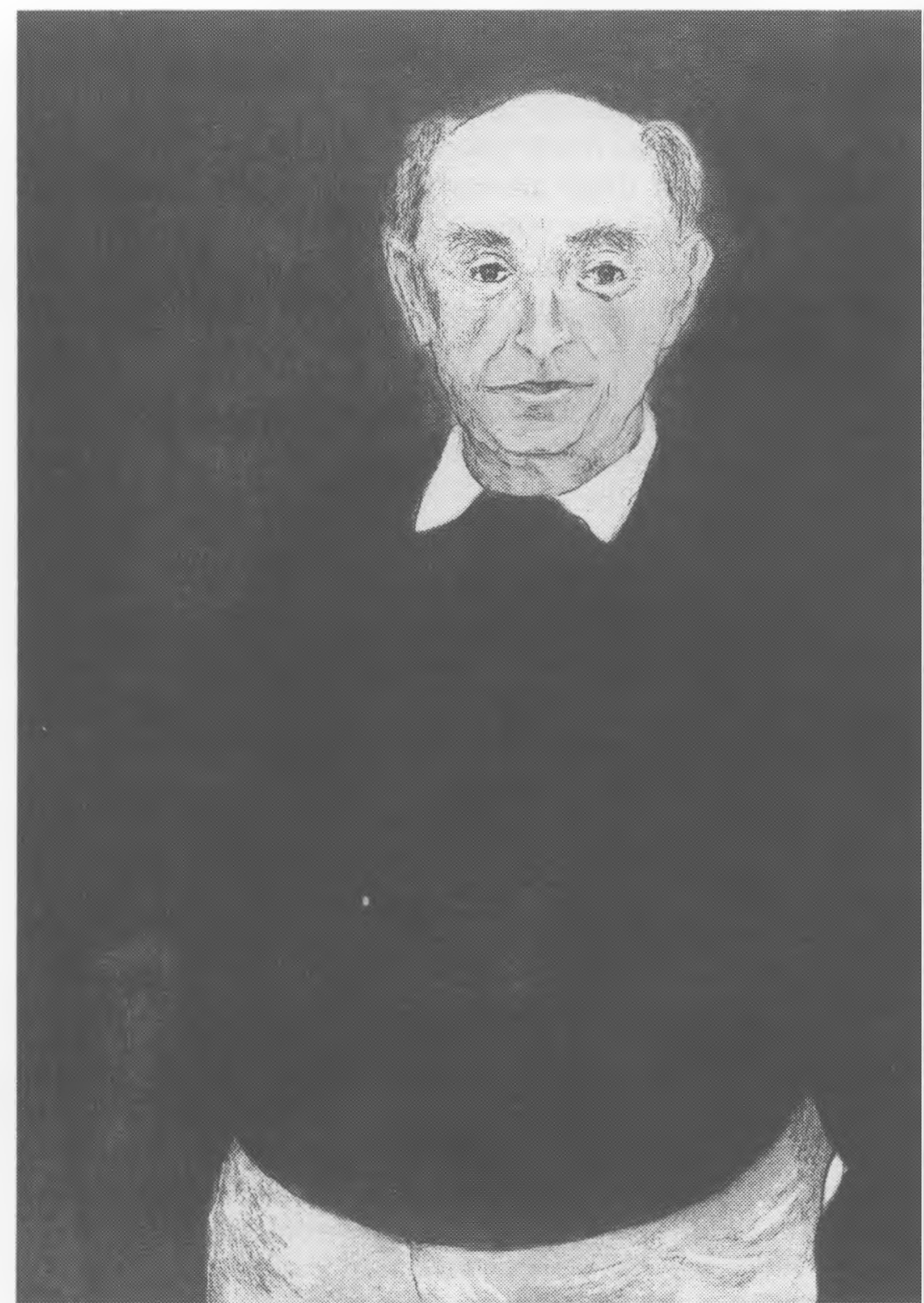

Gustav Bergmann, a portrait by Leola Bergmann entitled "My Husband at Seventy." Reproduction of her color intaglio print. 
that psychologists must restrict themselves to an examination of the relationships between the value of physical variables (as must all natural scientists), he did not believe, contrary to the claims of some behavioral psychologists (most notoriously, B.F. Skinner), that there are no mental (nonphysical) things and events, such as perceptions, thoughts and desires. This rejection of "metaphysical behaviorism" was closely tied to Bergmann's abandonment of logical positivism, a topic to which I now turn.

The logical positivists who first molded Bergmann's thinking, and among whom he no doubt counted himself even until, perhaps, the late 1930s or early 1940s, did not constitute an ideologically monolithic group. Nevertheless they shared a basic outlook, similar philosophical goals and even, as Bergmann himself was later to emphasize, a number of philosophical beliefs. Primarily they shared a respect for the achievements of mathematics and natural science, as well as the desire to see the former "demystified" - by being demonstrated to be an extension of logic-and the latter extended to encompass psychology and the social sciences.

The less positive, indeed the negative, side of logical positivism involved the emphatic rejection of all previous types of philosophical inquiry, especially "metaphysics", construed as a purely rational and a priori (that is, non-empirical) inquiry into the most general and pervasive features of reality. A similarly negative attitude toward theology, ethics, aesthetics and other forms of non-scientific theorizing was widely accepted. Even those positivists who had extremely strong ethical, political or aesthetic "opinions" were philosophically committed to the view that the assertions by means of which such opinions would be expressed are themselves really "pseudostatements" that are empty of "cognitive content" in the sense that they do not, as do the statements of natural science, represent states of affairs which, if actual, make the statements true (and if not, make them false).

If one were to encapsulate these attitudes in propositions, the following would perhaps serve as well as any: 
(1) All "necessary truths", propositions whose truth can be determined by reason alone without recourse to experienceand especially the propositions of mathematics-are "analytic". That is, they can be shown to be, given the proper definitions of the words by means of which they are expressed, instances of principles of logic.

(2) The claims and theories of traditional philosophy-and especially those of metaphysics - are either:

(a) really assertions whose truth can be determined by the empirical methods of natural science, or

(b) they are analytic, and are true in virtue of the definitions of the words used to express them, or

(c) they are "nonsensical" and really have no cognitive content at all.

Metaphysical claims were generally assigned to the last of these categories, usually with enthusiastic glee.

(3) Ethical and aesthetic statements and theories are, like those of traditional philosophy, pseudo-statements and possess no cognitive content. In general, any statements that (purport to) assert the value of something moral, aesthetic, political or otherwise, are all in the same boat; since the "truth" of such statements cannot be determined in a "scientifically respectable" manner, the only meaning they have is "expressive". That is, all such assertions "merely" express the feelings, desires and attitudes of the person who utters them; they do not represent anything, and thus cannot be true or false.

(4) The proper task of philosophy is clarification of the concepts employed by ordinary descriptive discourse and natural science. There is, presumably, no distinctive sort of metaphysical knowledge and there are no metaphysical theories; the only possible task remaining to philosophy is to display the logic of the concepts, make distinctions that will help prevent confusion, render ordinary language less ambiguous, more precise, and thus less likely to give rise to conceptual confusion. Many, if not all, of the positivists thought of metaphysics and the 
whole of traditional philosophy itself as a web of such confusions, and believed that it would simply disappear if language were rendered precise enough to make confusion about the logical form of the states of affairs represented by statements impossible.

These convictions must clearly be thought of as preludes to philosophical argument rather than the results of such argument; as they stand they are obviously very controversial and none of them is by any means obvious. To the logical positivists the less controversial Archimedean point on the basis of which these contentious claims were to be established was an amalgam of principles and beliefs known as "verificationism". Verificationists held that a statement (or a sentence purportedly used to make a statement) has "cognitive content", "descriptive meaning" or "literal meaning", if and only if it is verifiable, that is, if there is, at least in principle, some means by which its truth value (that is, its truth or falsehood) can be known. Thus a sentence such as "Julius Caesar had a mole on the inside of his right thigh" is, practically speaking, unverifiable; nevertheless, we can imagine what sorts of procedures and perceptions would tell us whether the statement expressed by the sentence is true or false; in knowing what would show the statement to be true we know the meaning of the statement. But other sentences, such as "The material world is an illusion", "Justice is better than happiness", or "The reason there is something rather than nothing is God's overflowing goodness", are all, presumably, not verifiable, since there is no procedure that could show them to be true (or false).

It should be obvious that the positivists could not hope to make out such claims without having a fairly precise conception of a "method of verification", for all of the above "nonverifiable" statements have been sincerely asserted, and asserted on the basis of thought, reasoning, and even, arguably, experience. The positivists did indeed struggle to make the verification principle precise enough to deny the status of "cognitively significant" to everything they felt was not a matter of sober, impartial, and rational inquiry while granting 
this status to everything they felt was. Since the latter category included the natural sciences and mathematics they had to come up with a formulation of their criterion that could encompass both of these very different sorts of statement.

Without going into the tortuous details of the many concerted attempts to find an adequate formulation of a meaning criterion that would do precisely what was expected of it and no more, the outlines of the effort are fairly straightforward. All meaningful statements were declared to be of one of either of two sorts of statement; one sort was called "analytic" and the other sort could be called "empirical". Empirical statements are either "observation statements", statements which describe what can be perceived or observed to be the case, or they are statements that can be shown to be true on the basis of evidence provided by observation statements. Analytic statements are statements that are either substitution instances of logical principles or they are statements that can be "reduced to" such statements by substituting defining terms for the terms they define. Consider, for example, the following logical principle:

(A) If something has all of a given set of properties, it has any one of them.

A substitution instance of this principle might be:

(B) If something is both unmarried and a male then it is unmarried.

Now suppose that we are given the following statement:

(C) If something is a bachelor then it is unmarried.

If we allow that the word "bachelor" is defined as anything (or anything human) that is both male and unmarried, then we can substitute the phrase "male and unmarried" for the term "bachelor" in (C), thus obtaining (B), a substitution instance of (A). And since (A) cannot be false (since it is a principle of logic), neither can (C).

The verificationists insisted that all (cognitively significant) propositions or statements that are not empirical are analytic 
(and vice-versa), and may thus be "reduced", in the abovesketched manner, to (substitution instances of) principles of logic.

Since mathematics is clearly composed of statements that are non-empirical, they must by the criterion be analytic. In Principia Mathematica, Bertrand Russell, who although not a logical positivist was greatly admired by them (and by Bergmann), presented a systematic attempt to demonstrate that the entire body of basic arithmetic could indeed be derived from logic, that is, that all the statements of arithmetic are analytic. Although there were many problems with his attempt (about which more presently), it was at first hoped and believed that they could be remedied with minor modifications of the basic program. The importance of the reduction of mathematics to logic consisted in the fact that mathematics had for centuries provided a kind of model of the perfect "science," a science, moreover, that applied to reality but whose theories were not established on the basis of an appeal to sense experience. The traditional metaphysicians whose works the positivists sought to consign to the trash heap could point to mathematics as an illustration of what they were doing; the only difference, presumably, was that mathematics investigated plurality, proportion and measure while philosophers investigated mind and matter, God and man, knowledge and truth, goodness and beauty, and the like. But if mathematics is construed, as the positivists would have us construe it, as a systematic derivation of the consequences of "mere" conventions - definitions - then it no longer provides an appealing model for those who want to acquire genuine knowledge to construe what they are doing as the acquisition of knowledge, for the "knowledge" of the mathematician on this view is not based upon any sort of rational insight into the abstract structure of reality but is, rather, merely an "unfolding" of conventional rules for using words, just as "bachelors are unmarried males" expresses the conventional meaning of the word "bachelor". While such an activity is, indeed, an extremely significant human skill, and one that is vital for the natural sciences, it is not itself a genuine 
form of knowledge. A mathematician cannot be said to have knowledge of, say, numbers, in the same sense that a biologist has a knowledge of animals or a physicist a knowledge of atoms.

However appealing verificationism once seemed, the entire program encountered insuperable difficulties. Much that the verificationist wanted to be considered meaningful was shown to be in fact meaningless by the formulations of the meaning criterion suggested by positivists. That is, much of natural science was shown to be non-derivable from observational evidence. Others showed, conversely, that sentences that are obviously nonsensical (Russell's example: "Green ideas sleep furiously") could in fact be shown to be cognitively significant by the criterion. Russell's attempt to derive mathematics from logic was finally recognized to involve many more serious difficulties than was initially realized, difficulties that according to most specialists are unsolvable in principle. And indeed, even if there had been no problem with his program, it would still not have advanced the basic viewpoint that the positivists hoped it would, for, as many critics of positivism have convincingly argued, reduction of an analytic statement to a substitution principle of logic only "shows" that statement to be true upon the assumption that that principle of logic itself is true. Attempts to further "reduce" these principles to substitution instances of yet further principles of logic are not only insuperably difficult but would clearly involve begging the question, for we would still need to know in general why principles of logic are true.

I have not given the details of all these objections and the counter-arguments they elicited because an understanding of them would require some expertise in logic. But one fairly straightforward objection to verificationism can, I think, be grasped by anyone. The objection attempts to focus the criterion upon itself asking "Is the verificationist criterion of meaning cognitively significant?" That is, is the statement "Only verifiable (i.e., analytic or empirical) statements are meaningful" itself meaningful? Clearly it is not an empirical truth; 
verificationists did not search through the statements that people have made, find those that are cognitively significant and then discover that each of them is either empirical or analytic. Nor, on the other hand, is it analytic; it certainly is not part of the meaning of "meaningful" that a meaningful statement must be either empirical or analytic. It follows that, by the verificationist criterion of meaning, the verificationist criterion of meaning is meaningless and that those, therefore, who espouse it are mouthing metaphysical nonsense.

The central convictions that dominate Bergmann's philosophizing may be placed into two groups: (1) his metaphilosophical views about what philosophy is and how it should be pursued, and (2) his metaphysical views proper, namely, his views about the nature of the contents and the general structure of reality.

As to the first and most significant of the former, Bergmann's fundamental precept clearly is what can only be called "the unavoidability of metaphysics". Classical philosophical problems, such as the mind-body problem, the nature of the causal relationship, the nature of a priori knowledge and deductive reasoning, or the status of principles of moral value, cannot be seriously addressed unless one adopts, perhaps covertly or implicitly, some philosophical opinion about the issue in question. One may, for example, come to believe that the mental states of people are identical to the states of their brains, or that a person's mental states are nothing more than that person's tendencies to behave in certain ways. In either of these cases one would be a "materialist". Or one may, on the other hand, insist that a person's mental states, while causally related to both brain states and behavior, are identical to neither; in this case one is a "dualist". One may even be led, as Bergmann himself was for a considerable portion of his philosophical career, to embrace the view that "everything is mental", in the sense that all that exists are sense data, the properties of and relations between sense data, and other mental states like perceiving, remembering and believing. In this case, one is (a certain sort of) "idealist". Finally, one may believe that all that exists are entities somewhat like sense data but which may be 
considered either mental or non-mental depending upon the context in which they are considered; this view is called "neutral monism".

The important point here is that whichever of these positions one adopts, Bergmann felt, one must hold one of them (or perhaps some variation of one of them) if one seriously engages the problems and issues involved. To glibly assert that "the mind-body problem is a pseudo-problem" is simply an inadequate response to these issues and problems, and it betrays an unwillingness to deal with them articulately. Bergmann accused many of the positivists of holding various of these classical metaphysical positions, but of doing so implicitly and therefore inarticulately, largely because they were unwilling to admit that what they were engaged in was metaphysics, a systematic attempt to describe the general structure of reality.

Bergmann's second metaphilosophical conviction is his conception of proper philosophical method. Bergmann believed that traditional philosophical theories were expressed with nonliteral uses of words (he called them "philosophical uses"). When a philosopher asserts that "Reality is spiritual", "Only matter exists", or "Human beings can have no knowledge", he or she is using the words in these sentences (at least some of them) in a figurative, non-ordinary sense. Literally speaking, there are a great many things in the universe that are not "spiritual" (for example, the chair on which I am now sitting), many things that are not "material" (for example, my present perception of the pen I am using to write this sentence), and there are certainly some things I could be said to "know" (for example, that the pen with which I am now writing contains blue ink). Anyone who seriously asserted the propositions in question, while taking them literally, would be, not simply wrong, but quite insane. But, Bergmann claimed, philosophers were not speaking literally when they made these claims; they were, rather, trying to press ordinary words into the service of philosophy, a somewhat extraordinary service for which their original roles in ordinary language do not prepare them. 
But what, then, is philosophy, and what are philosophers trying to do by using ordinary expression in extraordinary ways? According to Bergmann they are indeed trying to describe the world, but only in a very general and indirect manner. The manner of description employed by philosophers is displayed by Bergmann's method, the "ideal language method", a technique employed by several of the positivists, as well as Bertrand Russell, perhaps Wittgenstein (although he denied it), and other early twentieth-century linguistic philosophers. The technique involves using formal languages, artificial calculi. The motivation for using such calculi is the relative precision of their syntax and semantics. The "logical grammar" (i.e., the syntax) of a formal language makes completely explicit the logical structure of the objects and facts which the language is used to describe. In ordinary language sentences representing facts with entirely different sorts of logical form may be represented by sentences with nearly similar grammatical structures. Compare, for example: (a) "Mary is happy", and (b) "Cerberus is real". The former asserts of an individual object that it possesses a given property, the property of happiness. The latter, however, asserts something somewhat more complicated; it asserts that (if we follow Russell) "There is an object that is a three-headed dog guarding the gates of Hell and there is only one such object". A more "logically-perspicuous" language would make confusion on this point impossible; one would be able to simply "read off" the logical form of the objects and states of affairs represented by the sentences of the language. It was the belief of most positivists that traditional philosophy, especially metaphysics, was based upon the confusions generated by the imprecision and ambiguity of ordinary language, and that once such imprecision was rectified by a more precise language, there would be no more such confusion and metaphysics would whither away.

The third metaphilosophical conviction dominating Bergmann's thought is expressed by the "Principle of Acquaintance", the criterion that guides Bergmann's interpretation of his ideal language. The principle demands that the basic 
descriptive terms (names and predicates) of the I.L. schema can only designate things with which one is "acquainted," or things that are of the sort with (at least one example of) which one is "acquainted". The key term of the principle is doublequoted because its meaning is far from being ordinary or obvious. It is obvious that the principle is an attempt to capture the empiricism that Bergmann inherited from the logical positivists. Thus 'acquaintance' means 'experience', in some sense, and the Principle of Acquaintance is essentially the claim that a metaphysician should acknowledge the existence of no entities except those that he has experienced or that are of the sort he could experience. The natural way to interpret 'experience' is, of course, as 'perceive' (see, hear, smell, etc.), but Bergmann places more stringent requirements on the notion of acquaintance. As we ordinarily speak, we say "I see that the meter reads 130 degrees", "I see that the cup is on the table", "I heard the bone break during the collision", or even, much more loosely, "I see you're not feeling well today", or "I heard the neighbors having a party last night". The sorts of cases described by the last two sentences make it clear that we often speak, well within the bounds of ordinary usage, of perceiving something we didn't really perceive but only inferred from what we really perceived. But according to many philosophers, Bergmann included, even the sort of perception described by the first three sentences involves too much inference to really be considered the most "direct" sort of experience one might have. If I see the dial of a meter read 130 degrees then I infer from what I do see (or I assume) that this thing is indeed a meter, a complicated machine designed to indicate the varying "degrees" of some physical quantity or dimension. Most, if not all, of our ordinary perceptual experience of the world of material objects involves as much assumption and inference as "direct" or "immediate" experience.

Consider, for example, a case in which I see a red ball. This perception, like most, involves a great deal of reasoning; what I see may not be a ball at all, but a balloon, or a lawn ornament, or a danger signal from the gas company indicating a pipeline 
below the ground, or a thousand other things instead. We might try to excise the contents of my perceptual judgement that "extend beyond" what I really do perceive by replacing the statement that expresses my perception, "I see a red ball", with the statement "I see a red, sphere-like surface, and I believe that if I were to approach the object and examine it more closely I would see --etc.", where the 'etc' would be filled in by the sorts of things I would see if I were to examine the object properly and if it were indeed a red ball. If it is suggested that this could be done with all perception statements, then what is being suggested is that the immediate objects of perception are not material objects as such, but the front surfaces (namely, those facing the perceiver) of temporal cross-sections of material objects (namely, those portions of an object's history simultaneous with the perception of it). Even, however, if this suggestion is followed, it does not adequately excise reasoning from experience, for when I say that "I see a red-sphere-like surface" I am still making assumptions and inferences about what I see. I am assuming that the light is not of a hue that makes non-red things look red (and I am making similar assumptions about my eyes and brain). If nothing else, I am assuming that there is in fact a surface of something there; that is, that I am not simply hallucinating or dreaming.

In order to excise the interpretation of experience from experience itself the concept of acquaintance is simply understood as a type of direct experience of something that involves no conjecture or thought. According to many philosophers, including several of the positivists and the early Bergmann, the sorts of things with which one could be directly acquainted are colored and shaped areas, sounds (i.e., tones each of which has a pitch and a loudness), and other similar sorts of objects of immediate sensory experience (with no judgment made or presupposed about whether the experience is or is not hallucinatory). According to Bergmann himself, unlike all of the logical positivists, one is also directly acquainted with (one's own) "mental acts", such as perceivings, rememberings, believings, imaginings, and so on. That is, one's knowledge of 
one's own (present) mental states has exactly the same sort of noninferential immediacy as does one's awareness of the sorts of sensory data mentioned above; one does not engage in any sort of reasoning to figure out if one does have a given belief, memory or perception, although one may of course do so in order to discover if a belief or memory one has is correct.

Bergmann thus holds that metaphysics is unavoidable if one is to do philosophy at all, that the best and most articulate way it can be pursued is by construction of an ideal language in terms of which the entire world can in principle be represented, and that the constraints upon interpretation of such a language are provided by the Principle of Acquaintance.

Bergmann's metaphysics begins with what could be called "common-sense realism", a viewpoint embracing the following beliefs:

(1) the world contains a plurality of objects and sorts of objects. These objects can exist, and be known to exist, independently of other such objects. That is, the world is not one indissoluble, undifferentiated totality, an "Absolute", that can only be known "as a whole" (and thus which cannot really be known at all).

(2) The objects include trees, mountains, and atoms-which are usually called "material objects"; but they also include "persons", things that are conscious and that are capable of perceptions, rational thought and reasoning. The existence, properties and relationships of material objects do not depend upon the existence of persons; more particularly, the existence and the features of material objects do not depend upon the thoughts of persons. On the other hand, the mental features of persons-their perceptions, feelings and thoughts-can in no way be "identified with" or "reduced to" the physical features of persons' bodies, either the states of their brains or their tendencies to behave in certain ways.

(3) People can acquire knowledge of mind-independent reality by perception and reasoning. Scientists can acquire knowledge of the operations of nature, again, by perception and reasoning. 
For Bergmann, if not for others, common-sense realism must also include the following:

(4) What is known when one knows the truth of propositions of arithmetic, mathematics and logic is something that in no way depends upon the existence or thoughts of persons. Specifically, it does not depend upon linguistic conventions or the psychology of human computation and thinking. When I know that " $1+1=2$ " I know something about the relationships between these numbers, something that would exist even if people had never existed.

Although common-sense realism is where Bergmann begins, it is certainly not where his ontology ends. It is one thing to give a rough general description of the world of common sense; it is quite another to secure such a world from the philosophical attacks of absolute idealists, materialists, skeptics, conventionalists, and others who would undermine it. Specifically, what Bergmann tried to do is to show that one can depict or describe the world of common sense with an ideal language whose interpretation is constrained by the Principle of Acquaintance. What he wound up with is a philosophical outlook that might be called "critical realism" and which would probably not be called "commonsensical" by anyone.

To a nonphilosopher the most startling aspect of Bergmann's ontology would no doubt be his committed antisubstantialism. The term "substance" is used by philosophers to designate any particular thing that undergoes change (that is, a change of properties or relations) and yet remains the same thing through these changes; substances are also called, for this reason, "continuants". Clearly, most of the objects we deal with in everyday life, including ourselves, are substances. Many years ago I was small and light-haired, whereas now I am much larger and my hair is darker. I am nevertheless still the same thing, namely, myself. Obviously all animals and nonliving material objects are also substances, since such things, as we ordinarily think and speak, remain self-identical through changes of properties and relations. If one wanted examples of particular things that are not "substances" one might take a 
flash of lightning, a loud popping sound, a draft of wind, or anything that lasts only a moment. Such items can be characterized as "momentary particulars".

Bergmann argues that there are no substances, or rather, that a correct ontology cannot include substances. Another way of saying this-Bergmann's preferred way-is to say that substances are not designated by the names of an ideal language. His argument is more or less straightforward: I am not acquainted with substances. This claim seems to explicitly contradict that element of common-sense realism according to which we perceive, and thus acquire knowledge of, material objects. But Bergmann is arguing that our ordinary perceptual experience of material objects is not fundamental or basic, and that, therefore, everything that can be said about the objects of such experience can be said by speaking about ontologically fundamental things. In short, we can, Bergmann contends, "reconstruct" in principle whatever we say about things that endure through change by speaking about momentary things.

The momentary things in terms of which commonsense continuants are to be reconstructed are similar to, but not the same as, sensations or "sense data". A material object just is the temporal sequence of colored, shaped expanses that we experience when we perceive it; there is nothing "behind" or "underneath" this mosaic of appearances to which the appearances "belong" or in which they "inhere". That our ordinary conception of the world contains the concept of continuing substances is due to the greater simplicity of a world in which there are fewer particular objects; but this is just a "bookkeeping" device, and is, or should be, metaphysically irrelevant to the world insofar as we are "acquainted" with it.

Minds, or more traditionally "selves", are not treated much differently from non-mental substances. A mind is a temporal sequence of perceivings, rememberings, believings, desirings, and other "mental acts". And again, a mind is nothing "behind" or "beneath" this temporal sequence, a hidden something that "unifies" the states of consciousness that are, when we speak in an ordinary way, ascribed "to" a self. There are 
neither mental nor nonmental substances in Bergmann's world, even though everything we can say (and think) about such commonsensical items can, in principle, be said in a language whose vocabulary only allows us to refer to momentary particulars and their properties and relations.

Such a world may seem austere and sparsely populated when compared to the dense and "substantial" world of everyday life and of course in a sense this is true. But what disturbs most philosophers about Bergmann's ontology is not its sparseness but its lushness. Specifically, they object to what they, although not Bergmann himself, might characterize as his "Platonism". The term does not have a precise meaning, but very broadly, it designates anyone who believes in the existence of "abstract", as opposed to "concrete" entities. A concrete entity is, essentially, any entity that is "located" in space and time (or, at least, time), that is, which stands in spatial and temporal relations with other such entities. (Notice that both momentary entities and continuants are concrete in this sense!) But the properties of concrete entities, in some views (including Bergmann's), are not themselves similarly "in" space and time. Thus the red circle I see before me now stands in (a large number of) spatial and temporal relations to other particular objects; but its color and shape (circular) stand in no such relations. It would make no sense at all to wonder whether (or to assert that) red is to the left of green, or just prior to circularity.

Philosophers who object to abstract entities usually do so on the basis of what they take to be a "realistic" and empiricistic conception of the world. Something that isn't located any place or any time seems occult and mysterious. One is tempted to ask of abstract objects, "Well, if they're not in space and time, where are they?" The temptation lends strength to the objection. But Bergmann feels that unless we suppose that the properties of objects are nonlocalized and have a status equal to that of the objects that have them we will not be able to secure a realistic world view. To understand his reasoning we must consider the problem that gives rise to the issue. 
The world consists of a plurality of particular objects, but each of them is a kind of object; indeed, each particular object is of numerous kinds. One thing might be rubber, a ball, blue, inflated, spherical, resting on a rug, to the left of something red, and so on and so on. But now what is it about the object that makes it true that it is of these various kinds? One answer is that there is something which is in the object, or something to which the object is "connected"; this "something" is called a "universal". Blueness, sphericalness, and ballhood would thus be universals, in virtue of whose connection to which the above-mentioned particular is of the kinds that it is of.

Among those who find the notion of a universal repellent, one somewhat extreme contrary solution to the problem of grounding our classifications of things is the theory that, at bottom, our classification of objects is "arbitrary". That is, there is nothing "in" or "about" an object that makes it, say, blue, except the human convention that this thing is, according to our "linguistic conventions", the sort of thing to which the word "blue" is to be applied. In other words, there are no properties in addition to particular objects; there are only words which human beings apply to objects in accordance with rules of their own devising. According to this view, universal properties are the "shadows" cast by the words by means of which we classify things; but if we, and thus our words and the rules for applying them, were not to exist, neither would the properties of objects. There would just be the objects.

Bergmann rejects such an extremist view on the grounds of its conflict with realism; if the properties of objects are dependent on the classifying procedures of human beings then, in effect, human beings make objects have the properties we believe them to have. But then it would not be appropriate to claim that we can know what the features of mind-independent objects are, since objects would not have mind-independent features.

What is most distinctive of Bergmann's philosophy, however, is neither his anti-substantialism nor his acceptance of universals; it is rather his insistence that, as he puts it, "the 
form of the world is in the world". Part of what Bergmann means by this is that analytic propositions, propositions true in virtue of their "logical form", do describe reality; one might say that they describe the formal features of reality. Nevertheless they do describe something (i.e., they are genuine propositions) and what they describe, like everything else that is described by true propositions, is a part of reality, is in the world. But even more fundamentally what Bergmann means is that the formal characteristics of, and connections among, things belong to these things independently of our thought and discourse about them. Consider, for example, a given particular or a given property. Whatever properties the particular has, it seems that it must be true that it is a particular; similarly, whatever particulars have a given property it must be true that it is a property. What is attributed by these propositions could be called "formal properties" or even "formal universals". According to some philosophers the "fact" that a particular is a particular consists in nothing more than the linguistic fact that it is designated by a proper name (or a pronoun) of a given grammatical sort. And the "fact" that the property is a property consists in nothing more than the linguistic fact that it is designated (primarily) by a predicate. It goes without saying that if human beings did not exist the things in question would not be designated at all and thus, presumably, would be neither particular nor property. This would, however, once more violate Bergmann's strong realistic inclinations; he insists that when we know the logical form of something what we know is something that would be the case even if we were not to have thought of it.

Bergmann's realistic conception of logical form is complicated and extensive. Not only are the formal universals mentioned above to be treated in a realistic manner, but so are many other formal characteristics of things and facts. He contends that the connection between a particular and a property exists; in other words, he believes that the statement "this is red" designates a particular-this-connected to a universal-red-by an entity he calls "exemplification". Fur- 
thermore, he believes that the connections represented by statement connectives such as "and" and "or" are real entities. One might call all of these entities "formal relations". The distinction between what is represented by the names and predicates of a language (its descriptive vocabulary), on the one hand, and the "logical" terms such as the copula "is" and the statement connectives, on the other, is captured by the medieval distinction between "categorematic" and "syncategorematic" entities, respectively. It is extremely doubtful that any philosopher in history, and certainly none since the Middle Ages, has been such a partisan of the existence of the syncategorematic, i.e., formal, entities.

Bergmann has been criticized extensively by many other philosophers, including many of his own students and colleagues. It has been claimed that his key methodological ideas, the Principle of Acquaintance and the Ideal Language method, are not cogent. For example, it has been claimed that the idea of theory-free experience-acquaintance-is incoherent, that there simply is no such thing. It has also been claimed that the ideal language is an absurdity, that if it were possible to construct a metaphysically perspicuous schema then it would not be necessary while if it is necessary then it is not possible. Even more pertinently, it has been argued that Bergmann has misused these ideas. For example, it has been argued that Bergmann claims that he is acquainted with things that no one else experiences, things such as formal universals, secondorder universals and bare particulars (i.e., momentary particulars). It could be argued that Bergmann violates his own principles for using the ideal language. For example, in his early use of the method his claim is that what exists in the world is what would be designated by the undefined descriptive signs (names and predicates) of the ideal language. But then he goes on to attribute existence to entities that are presumably not designated by such signs, for example, "formal" entities that would be designated, if at all, by the "logical" signs (e.g., statement connectives) of the ideal language. 
Much worse than criticism, however, is apathy, and it must be admitted that Bergmann's philosophical concerns and the general style of his approach to issues are not presently very popular among philosophers (if, indeed, they ever were). A great many contemporary philosophers talk about history, about sociology and psychology and linguistics and literary criticism and apparently about everything except reality itself, which, one supposes, constitutes a sort of back-handed victory for the positivists who sought to bury metaphysics. Nevertheless, Bergmann's metaphysics certainly has the feel of something that will resurface at whatever point in the future philosophers return to philosophy from the armchair social science and quasi-political propagandizing that presently occupy their attentions. 